\title{
Crónica de la jurisprudencia europea sobre igualdad (De 1/9/2017 a 31/8/2018)*
}

\author{
Chronicle of the European case law on equality \\ (from $1 / 9 / 2017$ to $31 / 8 / 2018$ )
}

JEAN JACQMAIN

Profesor Jubilado de la Universidad Libre de Bruselas

doi: https://doi.org/10.20318/femeris.2019.4771

\begin{abstract}
Traducción de José Fernando Lousada Arochena (Magistrado especialista del Orden Social del Tribunal Superior de Justicia de Galicia, Profesor asociado de Derecho Procesal de la Universidad de A Coruña)*, María Gema Quintero Lima (Profesora titular de Derecho del Trabajo y de la Seguridad Social de la Universidad Carlos III de Madrid) ${ }^{* * *}$, y Ricardo Esteban Legarreta (Profesor titular de Derecho del Trabajo y de la Seguridad Social de la Universidad Autónoma de Barcelona) ${ }^{* * * *}$
\end{abstract}

Resumen. El estudio aborda el análisis de las sentencias dictadas en aplicación del principio de igualdad de trato y oportunidades desde el 1 de septiembre de 2017 hasta el 31 de agosto de 2018 por el Tribunal de Justicia de la Unión Europea. También incluye sentencias y decisiones dictadas en ese periodo por el Tribunal Europeo de Derechos Humanos.

Palabras clave: Tribunal de Justicia de la Unión de Europea, Tribunal Europeo de Derechos Humanos, Principio de igualdad de trato y de oportunidades.

Abstract. This paper deals with the analysis of judgments related to the principle of equal treatment and opportunities and delivered from September 1, 2016 until August 31, 2017 by the Court of Justice of the European Union. It also includes judgments and decisions on the subject during this period issued by the European Court of Human Rights

Keywords: Court of Justice of the European Union, European Court of Human Rights, Principle of equal treatment and opportunities.

\footnotetext{
"El texto original en francés se publicó en Journal de Droit Européen, Noviembre de 2018, págs 362 y ss. La crónica comprende sentencias y decisiones del Tribunal de Justicia de la Unión Europea y del Tribunal Europeo de Derechos Humanos. Si usted desea realizar comentarios, los puede enviar a jean.jacqmain@cgsp.be .

"* De la Parte I "igualdad de género", ha traducido los epigrafes 1 "igualdad en las condiciones de trabajo", 2 "igualdad en la seguridad social obligatoria", y 5 "permiso parental"; y ha acometido también una revisión general conjuntamente con Jean Jacqmain, autor del estudio.

${ }_{* * *}^{*}$ De la Parte I "igualdad de género", ha traducido los epígrafes 3 "protección de la maternidad", y 4 "permiso de paternidad".

${ }^{* * * *}$ Ha traducido integramente la Parte II "otras discriminaciones".
} 


\section{PARTE I. IGUALDAD DE GÉNERO}

En el ámbito legislativo nada que informar pues sigue debatiéndose en los órganos pertinentes la propuesta de una directiva destinada a mejorar la conciliación entre la vida laboral y familiar (COM (2017) 253 final).

En el ámbito jurisprudencial, se aprecia un curioso movimiento de péndulo: de 2016 a 2017 apenas comentamos un par de casos sobre discriminación de género ${ }^{1}$; mientras de 2017 a 2018, arco temporal de la presente crónica, la discriminación de género (en particular, aspectos relacionados con la maternidad, la paternidad y el permiso parental) provocó más actividad judicial que las otras discriminaciones aludidas en el artículo 19 TFUE.

\section{Igualdad en las condiciones de trabajo}

\subsection{Sentencia TJUE de 18 octubre 2017, Kalliri, C-409/16}

Por primera vez, el Tribunal de Justicia ha tenido que lidiar con un problema que en el pasado ha provocado vacilaciones considerables en algunos Estados miembros (como Bélgica). Las reglamentaciones griegas sobre admisión en la academia de policía requieren que el candidato, cualquiera que sea su sexo, alcance una talla mínima igual a 1,70 metros. Rechazada porque no alcanzó este umbral, una candidata inició un procedimiento de quejas en el curso del cual el Consejo de Estado griego interroga al Tribunal de Justicia.

Dado que la decisión negativa impugnada se remonta a 2007, era aplicable todavía la Directiva 76/207/CEE; el objeto de la controversia se refiere a las condiciones de acceso al empleo, de acuerdo con su artículo 3. Vista la uniformidad para ambos sexos de la medida en cuestión, el TJUE establece que la discriminación de género es indirecta. Su existencia no le genera duda ya que la condición de 1,70 metros descalificó a un número mucho mayor de mujeres que de hombres, como constató el Consejo de Estado; tanto mejor, podríamos decir, a la vista de las exigencias minuciosas que el TJUE establece para las demostraciones estadísticas en casos recientes.

Queda por proporcionar al tribunal nacional la información necesaria para examinar la justificación de la discriminación indirecta. El Gobierno griego invocó el cumplimiento de las tareas de la policía, a las que se aplicaba una condición de aptitud física tal que la talla mínima sería necesaria y adecuada. El TJUE se refiere a las sentencias que ha emitido sobre el mismo tema, pero en relación con el criterio de la edad máxima para el reclutamiento a la policía, a la luz de la Directiva 2000/78/CE. Señala que hasta 2003, el criterio de tamaño era diferente para hombres $(1,70)$ y para mujeres $(1,65)$, y en las fuerzas armadas, en particular, un mínimo de 1,60 se aplica linealmente, por lo que la razón propuesta no le resulta relevante.

\footnotetext{
${ }^{1}$ Véase Jean Jacqmain, “Crónica de la jurisprudencia europea sobre igualdad de género (de 1/9/2016 a 31/8/2017)", Aequalitas: Revista jurídica de igualdad de oportunidades entre mujeres y hombres, núm. 41, 2017, págs. 20-21.
} 
La Sentencia no ofrece sino en filigrana una respuesta a las dudas evocadas más arriba. Estas dudas surgieron precisamente de la implementación de la Directiva 76/207/ CEE y del temor a que el mantenimiento de mínimos diferenciados constituyera una discriminación directa contra los hombres; además, las mismas dudas se extendieron a los umbrales de rendimiento en las pruebas físicas impuestas durante el reclutamiento para ciertos servicios públicos. La solución pareció ser la adopción de criterios uniformes, pero estos crearon un riesgo de discriminación indirecta contra las mujeres, como acabamos de ver. De hecho, el caso anotado ilustra, si no una laguna, al menos una falta de pedagogía en las directivas sucesivas: autorizan una excepción a la igualdad de trato cuando el sexo sea una "condición determinante" para el ejercicio de actividad profesional (artículo 2, apartado 6, de la Directiva 76/207/CEE; artículo 14, apartado 2, de la refundición 2006/54/ $\mathrm{CE}$ ); pero nada se dice sobre los efectos de meras características naturales que, total o parcialmente, difieren de sexo a sexo.

Oportunidad pérdida: Poco antes del Tribunal de Justicia, el Tribunal Europeo de Derechos Humanos se pronunció sobre unos hechos similares. Una mujer fue despedida de un reclutamiento de psicólogos en una prisión lituana porque no alcanzó la altura mínima, establecida para mujeres a 1,55 metros y para los hombres a 1,60 metros; la justificación ofrecida del reglamento en cuestión consideraba que, por debajo de uno u otro de estos umbrales, los candidatos no disfrutarían de la buena condición física requerida para trabajar en un entorno penitenciario. El procedimiento que la demandante había seguido en vano ante los tribunales nacionales se refería únicamente a la pertinencia de estas disposiciones y, sin duda debido a la diferenciación de género, no se había mencionado la discriminación de género, aunque Lituania se adhirió a la Unión Europea el 1 de mayo de 2004, antes de los hechos del caso. El Tribunal de Estrasburgo declaró la solicitud inadmisible por falta de agotamiento de los recursos internos (Decisión de 11 julio 2017, Kužmarskiené vs. Lituania, Req. oㅜ 54467/12).

\subsection{Auto TJUE de 7 febrero 2018, Maturi et alii y Passeri, C-142/17 y C-143/17 acumulados}

En Italia, la edad legal de jubilación, más allá de la cual el empleador puede despedir de inmediato, era para bailarinas de ópera a los 47 años y para bailarines a los 52 años. En 2010 una reforma legislativa redujo y estandarizó la edad a los 45 años, pero una disposición transitoria permitió que las personas que habían sobrepasado esa edad solicitaran beneficios hasta los máximos anteriores, y por tanto diferentes.

Esta situación provocó una disputa al final de la cual la Corte de Casación de Italia invitó al Tribunal de Justicia a interpretar el artículo 14.1.c) de la Directiva 2006/54/CE, que prohíbe la discriminación de género en condiciones de empleo y trabajo, incluyendo el despido. Al TEDH le bastó un auto para responder a una solicitud tan simple pues el esquema de transición ahora discriminaba directamente a las mujeres. Lo más llamativo es que solo se cite en la fundamentación un antecedente judicial, ciertamente el más reciente sobre el tema, pero un antecedente particularmente torturado (STJUE de 18 noviembre 
2010, Kleist, C-356/09); cuando es que la posición del TJUE se remonta a más de treinta años (SSTJUE Roberts, 151/84; Marshall I, 152/84; Beets-Proper, 262/84).

\subsection{Sentencia TEDH de 19 junio 2018, Demirel vs. Turquía, Req. $n^{\circ} 30733 / 08$}

Esta STEDH se refiere al acceso de las mujeres a guardias de seguridad en la compañía de electricidad estatal en Turquía, siendo una cuestión sobre la cual el TEDH enfrentó un caso similar casi en todos los aspectos unos cuatro años antes (STEDH de 2 diciembre 2014, Boyraz vs. Turquía, Req. n 61960/08²). Inevitablemente en línea con ese precedente, concluyó por unanimidad que la imposición de la condición de "haber realizado el servicio militar", o más crudamente "ser un hombre", dió lugar a una violación del artículo 14 del Convenio Europeo de Derechos Humanos combinada con el artículo 8 (vida privada); cinco jueces contra dos también encontraron una violación del artículo 6.1 (juicio justo), en relación con el razonamiento de una decisión del Tribunal Supremo Administrativo dictada durante el proceso nacional. La solicitante recibe una compensación de $11.000 €$ por daños no pecuniarios y no pecuniarios.

Observamos con preocupación que, si bien el TEDH tardó seis años (2008-2014) en decidir el primer caso, tomó diez (2008-2018) en el segundo, obviamente más fácil de resolver dado que se limitó a seguir el precedente.

\section{Igualdad en la seguridad social obligatoria}

\subsection{Sentencia TJUE de 9 noviembre 2017, Espadas Recio, C-98/15}

En 2012, el Juzgado de lo Social 33 de Barcelona obtuvo unas respuestas precisas y útiles del Tribunal de Justicia sobre los efectos discriminatorios del trabajo a tiempo parcial en relación del derecho a una pensión de jubilación (STJUE de 22 noviembre 2012, Elbal Moreno, C-385/1133). Acaba de tener el mismo éxito ahora respecto a prestaciones por desempleo.

De acuerdo con la legislación española, la duración del derecho a las prestaciones de desempleo depende de los días cotizados, independientemente de la distribución de la jornada. Con esta regla, en el caso de un trabajo a tiempo parcial vertical (es decir, solo ciertos días de la semana), solo se tienen en cuenta los días de actividad; mientras que esta reducción no opera si hay un régimen horizontal (todos los días). La trabajadora en cuestión, una limpiadora que pertenecía a la primera categoría, solo obtuvo 420 días de beneficios por desempleo, mientras que, si atendesiemos a su período de cotización, se habrían justificado 720 días.

\footnotetext{
${ }^{2}$ Ver Jean Jacqmain, “Crónica de la jurisprudencia europea sobre igualdad de género (de 1/9/2014 a 31/8/2015)”, Aequalitas: Revista jurídica de igualdad de oportunidades entre mujeres y hombres, núm. 37, 2015, págs. 18-19.

${ }^{3}$ Ver Jean Jacqmain, “Crónica de la jurisprudencia europea sobre igualdad de género (de 1/9/2013 a 31/8/2014)", Aequalitas: Revista jurídica de igualdad de oportunidades entre mujeres y hombres, núm. 35, 2014, pág. 9.
} 
El TJUE señala de entrada que la situación controvertida implica un régimen legal de Seguridad Social no incluido en el ámbito de aplicación de la Directiva 97/81/CE relativa al Acuerdo marco sobre el trabajo a tiempo parcial. Si existe discriminación, se basa en el género y cae dentro del ámbito de aplicación de la Directiva 79/7/CEE sobre la igualdad de hombres y mujeres en los regímenes legales de Seguridad Social.

Claramente se manifiesta la diferencia en el tratamiento entre las dos categorías de trabajadores a tiempo parcial descritas anteriormente. El Juzgado de lo Social dijo que uno y otro incluyen entre el 70 y el $80 \%$ de las mujeres, lo cual no es objeto de ninguna contestación. Así las cosas, el Tribunal de Justicia no tiene aquí oportunidad para entrar en las argucias estadísticas que, en ocasiones anteriores, habían determinado un fuerte retroceso en su jurisprudencia ${ }^{4}$ : en el caso enjuiciado la discriminación indirecta de las mujeres por referencia a los hombres resulta ser obvia.

Como justificación objetiva, el Gobierno español presenta únicamente el principio de proporcionalidad. Sin embargo, como señaló la Abogada General E. Sharpston, el argumento no se sostiene, ya que los individuos en cualquiera de las dos categorías han contribuido con cotizaciones a tiempo parcial y por la misma duración temporal. Sus conclusiones también merecen atención porque señalan, por un lado, que a menudo el empleador impone el programa de tiempo parcial vertical, y por el otro el resultado de la regulación impugnada deviene (como en Elbal Moreno) en una doble desventaja para la persona interesada, ya que la prestación por desempleo en sí misma se basa en una remuneración necesariamente incompleta.

Por lo tanto, el TJUE resuelve que el artículo 4.1 de la Directiva 79/7/CEE, que prohíbe la discriminación de género en el cálculo de los beneficios en los regímenes legales de Seguridad Social, excluye una tal regulación.

\subsection{Sentencia TJUE de 26 junio 2018, M.B., C-451/16}

Con la espada del Tribunal de Estrasburgo en los riñones (STEDH, Gran Sala, de 11 julio 2002, Goodwin vs. Reino Unido e I. vs. Reino Unido, reqs. n² 28957/95 y 25680/94), el Reino Unido se vio obligado a modificar en 2005 su legislación para permitir la rectificación del estado civil después de un cambio de sexo. Una Sentencia posterior, esta vez del Tribunal de Luxemburgo (STJUE de 27 abril 2006, Richards, C-423/04), conoció del caso de un hombre que se convirtió en mujer, pero que no se pudo beneficiar de esa reforma y, en consecuencia, no pudo jubilarse en el plan de pensiones reglamentario a los 60 años, la edad normal para las mujeres (en lugar de 65 para los hombres); el Tribunal de Justicia encontró discriminación directa prohibida por artículo 4.1 de la Directiva 79/7/CEE.

${ }^{4}$ STJUE de 14 abril 2015, Cachaldora Fernández, C-527/13, que analizamos en "Crónica ... (de 1/9/2014 a 31/8/2015)", citada, págs. 19-20; y Auto TJUE de 17 noviembre 2015, Plaza Bravo, C-137/15, que analizamos en "Crónica de la jurisprudencia europea sobre igualdad de género (de 1/9/2015 a 31/8/2016)", Aequalitas: Revista jurídica de igualdad de oportunidades entre mujeres y hombres, núm. 39, 2016, pág. 8. 
Las personas transexuales, sin embargo, todavía tenían que enfrentar la resistencia de la legislación a asumir el cambio de las prácticas sociales. El cambio de estado civil permitido en la legislación británica exigía que el solicitante de cambio de sexo registral no estuviera casado en el momento de su solicitud; era necesario, pues, que anulara o disolviera su previo matrimonio heterosexual. Condición que desapareció en 2014, cuando la legislación británica autorizó el matrimonio entre personas del mismo sexo.

Aunque M. B. se convirtió en mujer, M. B. y su esposa rechazaron (por motivos religiosos) la disolución de su matrimonio; por ello M. B. no consiguió el acceso al registro civil del cambio de sexo; y, como en el caso anterior, no pudo retirarse a los 60 años. El litigio subsiguiente llegó a la Supreme Court, que planteó cuestión prejudicial ante el Tribunal de Justicia.

Siguiendo la opinión del Abogado General M. Bobek, el TJUE decide que cuando una persona cumple con los criterios físicos, sociales y psicológicos impuestos para la reasignación de sexo, existe una discriminación directa en el sentido del artículo 4.1 de la Directiva 79/7, si además esta legislación le obliga a no encontrarse casado con alguien del sexo que ha adquirido.

\section{Protección de la maternidad}

\subsection{Sentencia TJUE de 19 octubre 2017, Otero Ramos, C-531/15}

La Directiva 92/85/CEE relativa a la protección de las trabajadoras embarazadas, que hayan dado a luz o en período de lactancia se construye en torno a tres ejes: los permisos, la defensa del derecho al trabajo y la protección contra los riesgos laborales. La Directiva presta mucha atención a este último aspecto pues no en vano es uno de los instrumentos específicos adoptados a partir de la Directiva Marco 89/378/CEE relativa a la protección de la seguridad y salud en el trabajo. Sin embargo, el Tribunal de Justicia no había tenido nunca ocasión de pronunciarse sobre este aspecto; la laguna viene de ser llenada, aunque en un aspecto estrecho.

Asignada a un servicio de urgencias de un hospital español, una enfermera que se reincorpora al puesto después de disfrutar de su permiso de maternidad, informa al empresario de que está alimentando a su bebe mediante lactancia natural, razón por la que debería beneficiarse de medidas de protección de riesgos laborales y adaptación de las condiciones laborales. La solicitud fue rechazada en la medida en que el hospital consideró que el puesto que ocupaba no comportaba ningún riesgo para la trabajadora que fuera madre lactante. La Dirección Provincial del Instituto Nacional de la Seguridad Social ratifica el análisis hecho por el empleador.

El litigio provocado por sendas negativas termina en un recurso de suplicación ante el Tribunal Superior de Justicia de Galicia, que es quién plantea al Tribunal de Luxemburgo varias cuestiones relativas al alcance de las reglas comunitarias. Sin embargo, aunque la esencia de los debates jurídicos se referían a la evaluación de los riesgos que había llevado 
a cabo el empleador, y sobre la que se apoyaba el rechazo a la petición de la trabajadora, las cuestiones prejudiciales se centran en la carga de la prueba desde la perspectiva de la interpretación del artículo 19.4.a) de la Directiva 2006/54/CEE (refundición), que dispone que, si se invoca discriminación por razón de género, las reglas de la prueba que fijan los apartados 1 a 3 se aplican también a las situaciones reguladas por la Directiva 92/85/CEE.

El Tribunal de Luxemburgo se apoya en las conclusiones de la Abogada General E. Sharpston para confirmar que el asunto está vinculado a la Directiva 2006/54/CE. En virtud de su artículo 2.2, la noción de discriminación por razón de género incluye cualquier tipo de trato desfavorable a las mujeres que esté ligado al embarazo o al permiso de maternidad en el sentido de la Directiva 92/85/CEE. El Tribunal extiende un poco más esa formulación para alcanzar los supuestos de lactancia natural, y lo hace invocando el objetivo de protección que persigue el Derecho de la Unión ${ }^{5}$. El artículo 19 de la Directiva 2006/54/CE es entonces aplicable a un litigio en el que una trabajadora en situación de lactancia natural afirma que "la evaluación de riesgos (llevada a cabo por su empleador) no se ha efectuado de conformidad al artículo 4 de la Directiva 92/85/CEE". Posteriormente incumbe a la trabajadora el aportar la demostración "prima facie" de la evaluación defectuosa, lo que permitiría presumir la existencia de una discriminación directa; y el empleador tendría entonces la carga de llevar a cabo la prueba en contra.

Sorprende la redacción tan general de estas afirmaciones puesto que, siendo el establecimiento hospitalario que interviene en el proceso una institución publica, la controversia no cuestiona el efecto directo vertical de las disposiciones citadas por el Tribunal de Justicia; se trata más bien de que la jurisdicción de reenvío verifique si las reglas nacionales de transposición, tal y como son interpretadas judicialmente, hacen excesivamente difícil el efecto útil de la normativa comunitaria. Pero el Tribunal de Justicia no ha retomado las conclusiones que la Abogada General había hecho al respecto.

\subsection{Sentencia TJUE de 22 febrero 2018, Porras Guisado, C-103/16}

Un litigio de una trabajadora embarazada despedida en el marco de un procedimiento de despido colectivo ha llevado al Tribunal Superior de Justicia de Cataluña a preguntar dos aspectos de la Directiva 92/85/CEE.

En su respuesta, el Tribunal de Justicia dice que el artículo 10.1 de la misma exige que la legislación nacional incluya ante todo el principio de prohibición del despido de una trabajadora embarazada, que ha dado a luz o en situación de lactancia, y no se limite a imponer una reparación (en este caso la nulidad del despido), si el empresario no demuestra que su decisión se sustenta en motivos no relacionados con el estado de la interesada.

En lo que se refiere a la interacción entre la Directiva 92/85/CEE y la 98/59/CE relativa a los despidos colectivos, el Tribunal afirma que no hay contradicción entre los dos in-

\footnotetext{
${ }^{5}$ Al respecto se cita la STJUE de 11 noviembre 2010, Danosa, C-232/09; véase un comentario en nuestra "Crónica de la jurisprudencia europea sobre igualdad de género (de 1/9/2010 a 31/8/2011)", Aequalitas: Revista jurídica de igualdad de oportunidades entre mujeres y hombres, núm. 29, 2011, págs. 9 y 10.
} 
strumentos normativos. A tenor del artículo 10.1 de aquella, la legislación nacional puede prever que un despido colectivo conforme a la segunda constituye un motivo ajeno al estado de la interesada; y a tenor del apartado segundo, puede admitir que el empleador se limite a invocar la medida colectiva cuando informa a la trabajadora de los motivos de la extinción contractual, siempre que indique los criterios objetivos usados para designar a los miembros de la plantilla concernidos.

Por último, el artículo 10.1 de la Directiva 92/85/CEE no impone que la legislación nacional asegure a las trabajadoras embarazadas, que han dado a luz o en lactancia, una prioridad en el mantenimiento del puesto de trabajo o recolocación previa al despido colectivo, pero tampoco se opone.

En numerosos aspectos, el Tribunal se muestra más expeditivo que la Abogada General E. Sharpston, que particularmente había observado que la formula "excepciones no inherentes al estado de la trabajadora" (artículo 10.1 de la Directiva 92/85/CEE), no se corresponde exactamente con la expresión "uno o varios motivos no inherentes a la persona de los trabajadores" (artículo 1.1.a) de la Directiva 98/59/CEE). La Abogada general deseaba también que el Tribunal de Justicia examinase la hipótesis en la que en el momento de la notificación del despido colectivo el empleador no hubiera sido informado del embarazo; como ese elemento no figura entre las cuestiones prejudiciales, el Tribunal no los aborda, lástima.

Cabe señalar con curiosidad que, respecto de las finalidades de la Directiva 92/85/ CEE el Tribunal se remite esencialmente a su sentencia Danosa ${ }^{6}$, lo que sigue alimentando nuestra perplejidad en la medida en que Danosa se refería no a una trabajadora asalariada, sino a una trabajadora autónoma.

\subsection{Auto TJUE de 21 marzo de 2018, Vadillo González, C-252/17}

En 2010, el Tribunal de Justicia analizó la curiosa figura del permiso de lactancia previsto en el Estatuto de los Trabajadores español. Se trata de una facultad de reducción diaria de la duración de la jornada de trabajo, hasta el noveno mes posterior al nacimiento, que ha seguido la evolución de las prácticas sociales para destinarse a los cuidados del menor, sea alimentándole o no mediante lactancia natural, de forma que se ha hecho accesible también al padre. Sin embargo, un trabajador asalariado no había podido disfrutar del permiso porque su esposa, trabajadora autónoma, no estaba cubierta por la regulación de la norma laboral. El Tribunal de Justicia consderó esta condición suplementaria impuesta a los varones como una discriminación en las condiciones de trabajo según la Directiva 76/207/CEE (STJUE de 30 septiembre 2010, Roca Álvarez, C-104/09)7.

Revisada, a la luz de esa Sentencia, la disposición entonces cuestionada, hoy establece que si los dos progenitores trabajan, solo uno de ellos puede ejercer el derecho.

\footnotetext{
${ }^{6}$ STJUE de 11 noviembre 2010, Danosa, C-232/09; con nuestro comentario sobre ella ut supra citado.

${ }^{7}$ Véase nuestra “Crónica ... (de 1/9/2010 a 31/8/2011)”, obra citada, pág. 9.
} 
En consecuencia, se podría pensar que un padre trabajador asalariado cuya mujer se encuentra en desempleo, podría disfrutar del permiso sin dificultad, pero sin embargo la jurisprudencia nacional se encuentra dividida en este punto. Ciertos órganos consideran que si uno de los miembros de la pareja no está ocupado, podrá cuidar del menor, de modo que no está justificado que el otro progenitor disfrute el permiso. En un nuevo litigio, el Juzgado número 2 de Cádiz se ha dirigido al Tribunal de Justicia, que no ha dedicado al asunto más que un breve auto.

En Roca Álvarez, el Tribunal había estimado que la información proporcionada por la jurisdicción nacional no le permitía concluir que la disposición cuestionada contradecía la Directiva 96/34/CE relativa al Acuerdo marco sobre permisos parentales. La situación sigue sin aclararse puesto que también esta vez el Tribunal declara inadmisible la cuestión en relación con la Directiva 2010/18/UE relativa al Acuerdo marco revisado.

En cuanto a la Directiva 2006/54/CE, el Tribunal constata que la regla inscrita en el Estatuto de los Trabajadores se aplica indiferentemente a los trabajadores femeninos y masculinos, con lo cual no hay discriminación directa, sin perjuicio de que pudiera deducirse algún tipo de discriminación indirecta. La jurisdicción española se limita a sugerir que, a la vista de la tasa de empleo inferior de las mujeres, son sobre todo los hombres los que se enfrentan a un rechazo del permiso en circunstancias parecidas. Esta imprecisión en la descripción de la desventaja particular a que se refiere el artículo 2.1.b) de la Directiva le sirve suficientemente al Tribunal para concluir también la inadmisibilidad de la cuestión respecto a este aspecto.

\subsection{Sentencia TJUE de 26 octubre 2017, H.B., T-706/16 P}

Las disposiciones de la Directiva 2006/54/CE se han aplicado por referencia en un asunto de la Función pública europea. Excluida de un procedimiento de promoción en la Comisión, una funcionaria presento diversas quejas, especialmente la incidencia negativa de su ausencia durante el permiso de maternidad; invocó a propósito de su reclamación el asunto Thibault del Tribunal de Justicia (Sentencia de 30 abril 1998, Thibault, C-136/95).

Resolviendo en apelación en sustitución del extinto Tribunal de la Función Publica, el Tribunal rechaza el argumento, aplicando el esquema que traza el artículo 19.1 de la Directiva en lo que se prefiere a la práctica de la prueba. Además de la realidad de su permiso de maternidad, la recurrente no aporta ningún otro elemento que pueda fundamentar una presunción de discriminación por razón de género ${ }^{8}$. El Tribunal observa también que el asunto no guarda relación con el caso francés Thibault, en el que, como consecuencia de su ausencia por maternidad, el sujeto de la causa no había podido ser objeto de evaluación y calificación necesaria para su promoción.

\footnotetext{
${ }^{8}$ El Tribunal de Luxemburgo hace referencia a las conclusiones del Abogado General Dámaso Ruiz-Jarabo Colomer en la STJUE de 23 septiembre 2004, Hectors, C-150/03 P.
} 


\subsection{Sentencia TJUE de 7 marzo 2018, DW, C-651/16}

Justificado por el objeto del litigio, se puede aún mencionar un asunto de libre circulación de trabajadores. La legislación letona prevé que la prestación de Seguridad Social que se abona durante el permiso de maternidad se calcula sobre la remuneración media que ha dado lugar cotizaciones a lo largo de un periodo de referencia de doce meses. Una trabajadora solo había estado ocupada en Letonia durante el último de esos meses, con anterioridad había prestado sus servicios para una institución de la Unión Europea y no había entonces cotizado en el régimen general. Su prestación de maternidad se calculó en relación a esos once meses a partir de una cantidad uniforme mínima como si no hubiera trabajado. Y su reclamación desencadena un litigio al hilo del cual la corte suprema interroga al Tribunal de Justicia.

Reenviando la solución del caso a una jurisprudencia constante ${ }^{9}$ y observando que Letonia no demostró la existencia de riesgo alguno para el equilibrio de su Sistema de Seguridad Social ${ }^{10}$, el Tribunal concluye que el artículo 45 TFUE (libre circulación de trabajadores) se opone a reglas nacionales que conduzcan a consecuencias como las acabadas de exponer.

\subsection{Decisión TEDH de 22 mayo 2018, Cristaldi vs. Italia, Req. $n^{\circ}$ 29923/13}

Ya en su momento hemos dado cuenta sobre la Sentencia Ornano del Tribunal de Justicia $^{11}$ referida a la indemnización especial que compensa los gastos que soportan los magistrados italianos en el ejercicio de su actividad profesional. A esta ventaja no se tiene derecho en caso de suspensión de la ejecución del servicio, aunque desde el 1 de enero de 2005 también se genera mientras se disfruta del permiso de maternidad. El rechazo a una solicitud de indemnización correspondiente a dos permisos de maternidad anteriores a esta fecha conlleva que una magistrada acuda ante el Consejo de Estado, que a su vez se dirigió al Tribunal de Justicia. En función de las disposiciones de la Unión que estaban en vigor en el momento de los hechos (la Directiva 76/207/CEE), el Tribunal concluyó que no hay discriminación por razón de género en la medida en que una jueza que se encuentre en permiso de maternidad se encuentra en una situación diferente de aquella en la que se hallan los colegas masculinos y femeninos que realizan su prestación de servicios. También en su momento consideramos que esta solución debería ser objeto de reexamen porque el actual articulo 2.2.c) de la Directiva 2006/54/CE asimila a una discriminación todo trato menos favorable ligado a la maternidad, y es una norma aplicable a todas las condiciones laborales incluso la remuneración.

${ }^{9}$ SSTJUE de 16 diciembre 2004, My, C-293/03; de 16 febrero 2006, Öberg, C-185/04; y de 4 febrero 2015, Melchior, C-647/13.

${ }^{10}$ Véase STJUE de 21 enero 2016, Comisión contra Chipre, C-515/14.

${ }^{11}$ STJUE de 14 de julio de 2016, Ornano, C-335/15; véase nuestra “Crónica ... (de 1/9/2016 a 31/8/2017)", citada, págs. 9 y 10. 
Otra magistrada ha planteado una controversia idéntica ante el Tribunal Europeo de Derechos Humanos. El departamento competente le había reclamado el reembolso de la indemnización judicial especial que le había sido mantenida durante un permiso de maternidad disfrutado en 2003. Cuando ella impugnó la reclamación de esas cantidades indebidas, el Tribunal Constitucional italiano había respondido que la ausencia de retroactividad de la modificación legal en vigor a partir del 1 de enero de 2005 no vulneraba la prohibición de discriminación por razón de sexo.

Ante el Tribunal Europeo de Derechos Humanos la recurrente invocaba el incumplimiento del artículo 1 del Primer Protocolo, junto al artículo 14 del Convenio Europeo. Alegaba una discriminación indirecta, y se comparaba con el conjunto de magistrados/as que no disfrutaban de un permiso de maternidad. Es un argumento que parece prudente en el Derecho de Estrasburgo (puesto que el TEDH suscribe ese análisis), pero que supone un retroceso respecto del Derecho de Luxemburgo si se considera que desde la sentencia Dekker ${ }^{12}$ el TJUE viene admitiendo que toda discriminación que se justificase en la maternidad era directa, bien es cierto que en materia de condiciones de reclutamiento, y no de remuneración.

El Tribunal Europeo de Derecho Humanos trae a colación la STJUE Ornano para contextualizar el caso, y después de dedicar un "análisis atento" de la legislación italiana aplicable a los hechos del supuesto, considera que, en tanto que la recurrente disfrutaba de un permiso de maternidad remunerado, sus colegas masculinos y femeninos que llevaba a cabo el servicio, soportaban los gastos correspondientes. Como la interesada no había sufrido ese perjuicio, se concluye que la demanda resulta inadmisible.

A pesar de esta aproximación más minuciosa que la del Tribunal de Justicia, nos quedamos sin saber en qué consisten los gastos reales importantes (4.105 euros por cinco meses de permiso de maternidad en 2003), y sobre todo, por qué el legislador italiano puso fin en 2004 a una exclusión que, según las dos jurisdicciones europeas, resultaba evidente por sí misma.

\subsection{Decisión de 16 enero 2018, Charron et Merle-Montet vs. Francia, Req. $n^{\circ} 22612 / 15$}

Ante el Tribunal Europeo de nuevo, una pareja de francesas planteo una petición fundada en los artículos 8.1 (derecho al respecto de la vida familiar) y 14 del Convenio Europeo. Su solicitud de fecundación asistida había recibido una respuesta negativa de un centro hospitalario universitario porque el Código de la Sanidad Pública no autoriza ese tipo de procedimiento más que para una pareja compuesta por una mujer y un hombre. Ellas habían considerado que resultaría en vano la reclamación ante los órganos jurisdiccionales nacionales por cuanto en una Sentencia del 17 de mayo de 2013, el Tribunal Constitucional había declarado que la ley de la misma fecha llamada "matrimonio para todos" no había impuesto la modificación de las disposiciones de salud pública cuestionadas. Sin embargo, el Tribunal Europeo ha inadmitido la demanda amparándose en la falta de agotamiento de las vías de recurso previas.

${ }^{12}$ STJUE de 8 noviembre 1990, Dekker, C-177/88. 
¿Habrían debido las interesadas en todo caso someter el asunto a los órganos jurisdiccionales administrativos para poner en juego el Derecho de la Unión Europea? Como la regla litigiosa se inserta en una legislación general, parecería imposible apoyarse en la Directiva 2000/78/CE (que se refiere al trabajo) para denunciar una discriminación por razón de orientación sexual. Ahora bien, si esta disposición relativa a las prestaciones sanitarias se considerase incluida en la categoría enfermedad ${ }^{13}$, ¿no sería pertienente aplicar la Directiva 79/7/CEE puesto que, necesariamente, es la presencia de un hombre en la pareja la que condiciona el acceso al procedimiento médico? A través de la cuestión prejudicial el Tribunal de Justicia habría podido verificar la validez de la frontera que ha trazado entre los criterios "sexo" y "orientación sexual"14.

\subsection{Decisión de 6 de febrero de 2018, Bonnaud et Lecoq vs. Francia, Req. $n^{\circ}$ 6190/11}

A modo de post-scriptum al asunto anterior, pero sin ningún vínculo con el Derecho Social, cabría añadir el caso de otras dos francesas que vivían en pareja, y que tenían cada una un hijo, fruto de un proceso de fecundación asistida desarrollado en Bélgica. Habían presentado solicitudes cruzadas de delegación de la autoridad parental, cada una respecto del hijo de la otra, a las que el juez de familia había accedido. Recurrida la sentencia por la Fiscalía de la República, esa decisión se anuló en apelación. Y el Tribunal Supremo confirmó la nulidad de la decisión.

Ante el Tribunal Europeo, las interesadas denunciaban una violación de los artículos 8 y 14 del Convenio. El Tribunal observa que el artículo 377.1 del Código Civil francés autoriza la delegación de la autoridad parental cuando particulares circunstancias de vida lo exijan, y que la aplicación que de él hace la jurisprudencia -como en el supuesto- no oculta sesgo alguno suscitado por la orientación sexual de los/las progenitores/as. Aún más, parece que a ojos de su entorno, las dos mujeres aparecían como la pareja de progenitoras de sendos menores. Finalmente, tras su separación, una ha reiterado su demanda, y la otra ha comenzado un proceso de adopción de la hija de la primera. Y, valorando todo ello, la demanda se inadmite.

\section{Permiso de paternidad}

\subsection{Decision de 12 de diciembre de 2017, Hallier e. a. vs. Francia, Req. $n^{\circ} 46386 / 10$}

Con anterioridad de la reforma legislativa francesa de 17 de mayo de 2013 mencionada más arriba, dos mujeres habían suscrito un pacto civil de solidaridad. Cuando una de ellas dio a luz, la otra solicitó ser beneficiaria del permiso de paternidad (11 días) indemnizado por el seguro de enfermedad. La Caja rechaza la solicitud, lo que desencadena un procedimiento judicial en el que, en todas las instancias, se rechaza la demanda; y en

\footnotetext{
${ }^{13}$ En este sentido, STJUE de 19 octubre 1995, Richardson, C-137/94.

${ }^{14}$ En la STJUE de 17 febrero 1998, L.J. Grant, C-249/96.
} 
último lugar por el Tribunal Supremo, que afirma que la disposición legal cuestionada se apoya en un criterio único de paternidad biológica, por lo que no se puede concluir que exista discriminación alguna.

Ante el recurso de las dos mujeres, el Tribunal Europeo declara inadmisible la demanda que denunciaba una violación de los artículos 8 y 14 del Convenio Europeo, al mantener que la regla cuestionada tenía por objeto "reforzar a los padres (biológicos) en su responsabilidad educativa respecto de sus hijos", objetivo legítimo que descarta todo riesgo de discriminación.

El objeto del litigio desapareció en 2012 al reconocerse que el otro miembro de una pareja que no sea el padre biológico tiene derecho a un permiso de acogida idéntico al de paternidad. Sin embargo el asunto ha sido una ocasión perdida de profundizar sobre una cuestión realmente seria.

Se puede leer en la decisión que las interesadas habían planteado simultáneamente su demanda ante el Tribunal de Estrasburgo, y una queja informal ante la Comisión Europea, que la había archivado sin darle curso, en especial porque se había planteado demanda en paralelo ante el TEDH.

Por otra parte, en la Sentencia de 11 de marzo de 2010 del Tribunal Supremo francés se observa que el Derecho de la Unión se había citado en el cuerpo, pero mezclado con otras disposiciones nacionales e internacionales. Hay que lamentar que ninguna jurisdicción francesa haya sido invitada u obligada, sobre la base del artículo 267 TFUE, a preguntar al Tribunal de Justicia acerca de una eventual discriminación fundada en el género, respecto al Derecho de la Unión. El criterio de la orientación sexual, también él, es obvio, pero habría resultado más difícil que entrara en juego, porque la Directiva 2000/78/CE no se aplica a los regímenes legales de Seguridad Social, del que deriva la prestación que genera la controversia.

El análisis que pudiera hacer el Tribunal de Justicia presentaría aún mucho más interés atendiendo a que la proposición de Directiva COM (2017) 253 mencionada más arriba contempla explícitamente la finalidad de animar una más efectiva implicación de los padres en las tareas de educación de los hijos, y lo hace, entre otras maneras, imponiendo a los Estados miembros que han de instaurar un permiso de paternidad de al menos 10 días. También se precisa que este derecho debe poder ejercerse sea cual fuere la situación matrimonial o familiar, fórmula que, según la exposición de motivos de la Comisión, pretende evitar toda discriminación entre parejas casadas o no casadas, homo- o heterosexuales. Esta corrección tan discretamente expresada es esencial para prevenir los efectos adversos con una excelente intención, tal y como se ilustra con la decisión comentada.

\section{Permiso parental}

\subsection{Sentencia TJUE de 7 septiembre 2017, H., C-174/16}

En la administración del Land de Berlín, un funcionario había aprobado la prueba de selección para acceder a un puesto directivo, sujeto a la finalización exitosa de una pasantía 
de dos años a completar de manera efectiva. Durante la mayor parte del tiempo estuvo en permiso parental, que continuó cuando supo que el trabajo en cuestión se había vuelto a sacar a concurso y se había asignado a otro funcionario. Al conocer de su recurso, el Verwaltungsgericht de Berlin presentó al Tribunal de Justicia varias cuestiones relativas a la Directiva 2010/18/UE (Acuerdo marco revisado sobre el permiso parental), así como acerca de las consecuencias que se deben extraer si el sistema nacional resulta ser incompatible con esta.

Adoptando la Opinión del Abogado General Mengozzi, el Tribunal responde con la mayor firmeza y precisión en aplicación de la cláusula 5 del Acuerdo Marco, cuyo apartado 1 garantiza el derecho a regresar al lugar de trabajo al final de la licencia parental, y el 2 el mantenimiento de los derechos en curso de adquisición al comienzo de este. Teniendo en cuenta los objetivos del Acuerdo marco, esas disposiciones prohiben el trato que el solicitante ha sufrido conforme a las normas nacionales; y el hecho de que la duración de la licencia parental alemana supere con creces el mínimo de 4 meses requerido por el Acuerdo marco resulta irrelevante.

Para hacer efectivo el rechazo a este tratamiento, el tribunal remitente debe asegurarse de que el funcionario en cuestión pueda continuar completando el período de prueba en el cargo al que había accedido; si, como argumenta el Land, esto resulta imposible por razones organizativas, debe asignarse a un puesto equivalente con las mismas perspectivas de nombramiento definitivo. Y se excluye que tenga que someterse a una nueva selección.

Dadas estas respuestas, el Tribunal se abstiene de examinar la posibilidad de discriminación indirecta de género en el sentido de la Directiva 2006/54/CE (al ser mujeres las principales usuarias del permiso parental). No obstante, dada la relativa proximidad de los hechos, se sugiere comparar la decisión aquí resumida con Napoli, que se refería a los efectos negativos de un permiso de maternidad en el progreso de una pasantía ${ }^{15}$.

\subsection{Sentencia TEDH de 3 octubre 2017, Enache vs. Rumanía, Req. nº 16986/12}

Fuera del ámbito de las relaciones laborales, el impacto de la maternidad, o la paternidad, se planteó inesperadamente ante el Tribunal Europeo de Derechos Humanos. En Rumanía, un hombre condenado a siete años de prisión había invocado sin éxito la aplicación a su favor de una disposición legal que permite a una madre solicitar el aplazamiento de la ejecución de la sentencia hasta el primer cumpleaños del hijo recién nacido.

En su demanda, basada en el artículo 14 del CEDH en relación con el artículo 8 (vida familiar), el Tribunal Europeo recuerda que, con respecto a la parentalidad, las situaciones de mujeres y hombres son comparables, como estableció en Markin vs. Rusia ${ }^{16}$. Sin embargo, una mayoría de cinco jueces contra dos admite que la diferencia de trato tiene una justificación objetiva, que el gobierno en cuestión afirma encontrar en el mejor interés del niño,

\footnotetext{
${ }^{15}$ STJUE de 6 marzo 2014, C-595/12; ver Jean Jacqmain “Crónica ... (de 1/9/2014 a 31/8/2015)”, citada, págs. 19-20.

${ }^{16}$ STEDH, Gran Sala, de 22 marzo 2012, Req. n 30078/06; ver Jean Jacqmain “Crónica de la jurisprudencia europea sobre igualdad de género (de 1/9/2011 a 31/8/2012)", Aequalitas: Revista jurídica de igualdad de oportunidades entre mujeres y hombres, ISSN 1575-3379, núm. 31, 2012, págs. 20-21).
} 
concretado por "los vínculos particulares que existen entre la madre y el niño recién nacido". La opinión concurrente del Presidente de la Sala, G. Yudkivska, enfatiza la importancia de la lactancia materna. Por el contrario, los disidentes P. Pinto de Albuquerque y M. Bošnjak subrayan que la posición mayoritaria contradice claramente la jurisprudencia Markin.

\section{PARTE II : OTRAS DISCRIMINACIONES}

Este año no ha habido ninguna evolución legislativa a mencionar. En el apartado de jurisprudencia, en Luxemburgo, al igual que en Estrasburgo, la discriminación por las convicciones al igual que por la edad ha requerido mucha atención de los tribunales, sin que quepa imaginar la jerarquización de las prácticas discriminatorias, todas ellas extremadamente perjudiciales.

\section{Discriminación por razón de la raza o del origen étnico}

\subsection{Decisión de 11 julio 2017, Dimitrova a.o. contra Bulgaria, Req. $n^{\circ} 39084 / 10$}

El pasado año había recaído una decisión de inadmisibilidad dictada por el Tribunal europeo respecto a personas gitanas expulsadas de viviendas insalubres en Rumanía

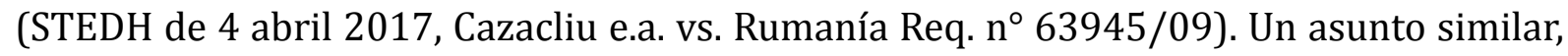
que implica a Bulgaría y que es el que ahora ocupa nuestro comentario, ha conocido una solución idéntica. En este caso, la expulsión y la demolición de las viviendas insalubres, llevada a cabo en invierno, había costado la vida a un bebé.

A diferencia del caso de Rumanía, los acontecimientos sucedieron en 2008, después de la adhesión de Bulgaria a la Unión Europea (1 de enero de 2007), disponiendo ese Estado de legislación para implementar la Directiva 2000/43/CE; no obstante, al resolver los recursos presentados por una asociación en nombre de las víctimas, las instancias jurisdiccionales nacionales no habían examinado el impacto de esta legislación. Resulta así de lamentar que la asociación no haya logrado forzar un debate sobre el fondo (¿por falta de experiencia en la puesta en marcha de sus vías de defensa?); lo que permite al TEDH constatar la falta de agotamiento de las vías internas de recurso, y con ello procede a la inadmisión de la demanda.

\section{Discriminación por razón de la edad}

\subsection{Sentencia TJUE de 28 febrero 2018, John, C-46/2017}

El Tribunal Regional de Trabajo de Bremen planteó diversas cuestiones prejudiciales ante el Tribunal de Justicia sobre el final de carrera de un profesor contratado. En 
virtud del convenio colectivo aplicable a la función pública de los Länder, la vinculación de servicio finaliza cuando la persona alcanza la edad en que puede acceder a la pensión de jubilación, si bien en el ámbito del sector educativo la relación de empleo puede prolongarse más allá de esa edad, hasta el fin del año escolar en curso, es decir, durante un periodo determinado. En este caso, el docente había solicitado tras la expiración de ese plazo, una prolongación de un semestre; y dado el rechazo de la entidad empleadora a su solicitud, decidió plantear un litigio.

Las cuestiones prejudiciales se fundamentaban principalmente en la Directiva 1999/70/CE relativa al Acuerdo marco sobre el trabajo de duración determinada; el TJUE responde que la cláusula $5 \mathrm{del}$ acuerdo no se opone a que una disposición nacional autorice una o diversas prórrogas de la contratación, subordinándolas al consentimiento de ambas partes.

Por otra parte, la jurisdicción alemana había evocado la incidencia de los artículos 2.2 y 6.1 de la Directiva 2000/78/CE, en relación con el criterio de la edad. El Tribunal de Justicia se refiere sin dudarlo a su Sentencia Rosenbladt ${ }^{17}$, en la que había validado la legislación federal que prevé de modo general la cesación automática de los contratos de trabajo a la edad de la jubilacion; el TJUE observa que el convenio colectivo en causa introduce, por voluntad de los interlocutores sociales, un elemento de flexibilidad que reconduce los intereses de las dos partes al contrato. No hay, de este modo, discriminación respecto al artículo 2.2 de la Directiva.

\subsection{Sentencia TJUE de 14 marzo 2018, Stollwitzer, C-482/16}

Eliminar las consecuencias de una antigua discriminación fundada sobre una edad mínima se revela una tarea ardua. En 2009 el Tribunal de Justicia había señalado ${ }^{18}$ que excluyendo del cálculo de la antigüedad los periodos de formación llevados a cabo antes de la edad de 18 años en la institución donde el trabajador había proseguido su carrera, las disposiciones legales austriacas contravenían el artículo 2 de la Directiva 2000/78/CE, sin poderse justificar tal opción a la luz de su artículo 6, número 1. Las correciones realizadas con posterioridad en la legislación austriaca aplicable a la función pública dieron lugar, a su vez, a impugnaciones ${ }^{19}$.

En cuanto a los ferrocarriles federales, a los que se les aplica una legislación distinta, un primer intento de rectificación había dejado subsistir la discriminación, como así lo había constatado el Tribunal de Justicia ${ }^{20}$.

Una nueva tentativa ha provocado un litigio adicional y además una cuestión ante el Tribunal de Luxemburgo planteada por el Tribunal de Apelación de Innsbruck. En esta ocasión, el legislador suprimió retroactivamente y para todos los trabajadores el umbral

\footnotetext{
${ }^{17}$ STJUE de 12 octubre 2010, Rosenbladt, C-45/09.

${ }^{18}$ STJUE de 18 junio 2009, Hütter, C-88/08.

${ }^{19}$ Que se examinaron en la STJUE de 11 noviembre 2014, Schmitzer, C-530/13.

${ }^{20}$ STJUE de 28 enero 2015, Starjakob, C-417/13.
} 
del 18 años, de modo que los periodos de actividad anteriores y posteriores a esta edad cuentan en adelante en la antigüedad baremada, pero a condición de que la experiencia adquirida gracias a esa prestación lo haya sido en empresas que operen en el mismo sector de actividad que el del empleador actual.

El Abogado General P. Mengozzi había concluido que este nuevo régimen era discriminatorio porque con anterioridad los periodos de formación realizados tras los 18 años entraban dentro de la antigüedad baremada, siendo igual el sector en el que se hubiesen realizado; mediante la cláusula de salvaguarda de los derechos adquiridos, los trabajadores que se habían beneficiado de esa toma en consideración, eran tratados de manera más favorable que aquellos trabajadores a los que afectaba la nueva condición.

Por el contrario, el Tribunal, separándose de las conclusiones del Abogado General, estima que el régimen impugnado satisface hoy día las exigencias de los artículos 2, 6 y 16 de la Directiva. Mediante las reglas nacionales que asimilan la prestación de servicios en el sector ferroviario de otro Estado miembro, el artículo 45 TFUE no se encuentra tampoco en cuestión.

\subsection{Sentencia TJUE de 3 mayo 2018, H.K. vs. Comisión, T-574/16}

Daremos cuenta aquí de un asunto de función pública europea. Una agente estatutaria de la Comisión Europea había vivido veinte años en concubinato con un ciudadano belga afectado de una grave enfermedad crónica cuyas necesidades ella atendía. La pareja contrajo matrimonio en 2014, pero once meses más tarde, falleció la esposa. En aplicación del artículo 17, apartado 1, del Anexo VIII del Estatuto de personal, que impone la condición de que el matrimonio haya durado al menos un año, la Comisión rechazó la concesión de una pensión de viudedad al cónyuge superviviente.

El Tribunal resuelve el recurso rechazándolo, declarando que la condición de acceso a la pensión no es ni arbitraria ni inadecuada. El Tribunal estima infundado el agravio fundamentado en el artículo 21 de la Carta de los Derechos Fundamentales de la Unión (el principio general de igualdad y no discriminación) y, por relación, en el artículo 2 de la Directiva 2000/78/CE, descartando como desprovista de pertinencia la alegación de la Sentencia Maruko del Tribunal de Justicia ${ }^{21}$, que se refería a una pensión de supervivencia de un régimen profesional de Seguridad Social, condicionado a la existencia de un matrimonio que, de acuerdo con la legislación alemana de aplicación, era vedado a las parejas homosexuales.

Por el contrario, el Tribunal de Justicia cita el precedente D. y Suecia vs. Consejo, en el que había confirmado ${ }^{22}$ que otra exigencia legal de matrimonio privaba legitimamente de asignación familiar a un funcionario masculino integrante, de acuerdo con su ley nacional, de una pareja registrada con un hombre. Diecisiete años más tarde, se constata que este mismo rigorismo mantiene su vigencia en la Comisión (salvo que, si nos atrevemos

\footnotetext{
${ }^{21}$ STJUE de 1 abril 2008, Maruko, C-267/06. Véase también la STJUE de 10 mayo 2011, Römer, C-147/08.

${ }^{22}$ Sentencia del 31 mayo de 2001, D. y Suecia vs. Consejo, C-122/99 P y C-125/99 P acumulados.
} 
a esperar ${ }^{23}$, se trate de un matrimonio homoxexual legalmente contraído en un Estado miembro no podría ser discutido por el Estatuto). Por otro lado, el Tribunal de Justicia comenta que la duración mínima de un año exigida para la concesión de una pensión de viudedad va orientada a la prevención de maniobras cuasi macabras de apropiación; tal consideración resulta singularmente insultante en este caso tan concreto.

En su conjunto, la Sentencia objeto de nuestro comentario genera la impresión de una profunda hipocresía desconectada de la realidad social ${ }^{24}$, a lo que se añade una indecorosa preocupación por el ahorro presupuestario.

\subsection{Sentencia TEDH, Gran Sala, de 5 septiembre 2017, Fábián vs. Hungria, Req. $n^{\circ} 78117 / 13$}

Para diversos Estados miembros de la Unión Europea la búsqueda del equilibrio presupuestario ha estimulado la adopción de medidas restrictivas en la función pública, especialmente en materia de jubilación. De este modo, la incompatibilidad del cobro de una pensión a cargo de Rumanía con los ingresos de una actividad asalariada en el sector público, al tiempo que esta acumulación de ingresos es posible si el trabajo se ejerce en el sector privado, había sido sometida al Tribunal de Justicia de la Unión Europea a través de una cuestión prejudicial, en relación con la incidencia que pudiera tener la Directiva 2000/78/CE. Dentro de los límites estrechos de esta Directiva, el Tribunal había concluido en $2015^{25}$ que no había una discriminación basada en la edad.

Por lo contrario, una Sala del Tribunal Europeo de Derechos Humanos había condenado a Hungría ${ }^{26}$ por una regulación similar, al constatar una violación del artículo 1o del Primer protocolo (derecho de propiedad) y una doble discriminación a la luz del artículo 14 de la Convención, cuya formulación abierta acoge criterios no previstos en la Directiva 2000/78/CE.

Sin embargo, el Gobierno implicado logró el reenvío del expediente ante la Gran Sala y esta última, por 11 votos contra 6, modificó el criterio precedente en la Sentencia que ahora comentamos dictada de conformidad con una jurisprudencia permisiva del Tribunal de Estrasburgo sobre las medidas nacionales de austeridad que implementan los acuerdos concluidos con las instituciones de la Unión y los organismos internacionales. La mayoría considera que la afectación al derecho de propiedad no se muestra excesiva, añadiendo además que las realidades en los sectores público y privado no son comparables; la perspectiva de la discriminación que resultaría de que la prohibición de acumulación no se aplica de modo uniforme en los servicios públicos, ni siquiera parece haberse examinado.

\footnotetext{
${ }^{23}$ Teniendo en cuenta la STJUE de 5 junio 2018, Coman e.a., C-673/16, dictada por el TJUE en materia de libre circulación de ciudadanos de la Unión Europea y de sus familias (Directiva 2004/38/CE).

${ }^{24}$ Comparar con la STJUE de 20 julio 2016, Michel-Deberghes vs. Comisión, F-104/15, relativo a esposos divorciados luego casados de nuevo. En el sentido del artículo 21 TFUE y la Directive 2004/38/CE, hay que tener en cuenta la convivencia de hecho: STJUE de 12 julio 2018, Banger, C-89/17.

${ }^{25}$ STJUE de 21 de marzo de 2015, S.C.M.D., C-262/14.

${ }^{26}$ STEDH de 15 diciembre 2015, Fábián v. Hungary, Req. $n^{\circ}$ 78117/13.
} 
Muy poco después, el Tribunal de Estrasburgo se refirió a esta Sentencia de la Gran Sala para declarar manifiestamente mal fundamentadas y por lo tanto no admisibles nuevas peticiones con un planteamiento similar ${ }^{27}$.

\section{Discriminación por razón de la discapacidad}

\subsection{Sentencia TJUE de 18 de enero de 2018, Ruiz Conejero C-270/16}

Aunque un trabajador había sido reconocido como persona con discapacidad a causa de una afección endocrina, que provocaba una obesidad a su vez generadora de crisis de lumbago, el mismo había sido empleado por una empresa española de limpieza. Su estado de salud provocaba periodos de incapacidad temporal de corta duración, aunque repetidos, cuyo total superaba el umbral más allá del que el Estatuto de los Trabajadores autoriza al empleador a despedir, lo que finalmente decidió la empresa. Tras la impugnación judicial del despido por parte del empleado, el Juzgado de lo Social de Cuenca plantea cuestión prejudicial a propósito de la compatibilidad de las reglas nacionales con la Directiva 2000/78/CE.

En sus conclusiones, la Abogada General E. Sharpston recomienda al Tribunal proceder en dos tiempos: en primer lugar, el Tribunal debería verificar si el Estado miembro ha tomado las medidas necesarias respecto al artículo 5 de la Directiva, ya que, a falta de ajustes razonables (o de la acreditación de la imposibilidad de su implementación), permitir el despido de un trabajador con discapacidad contravendría las exigencias de esta disposición; solo a continuación, el Tribunal debería examinar la validez de los motivos anticipados por el Gobierno de España para justificar la discriminación indirecta por discapacidad derivada de las reglas nacionales.

Sin embargo, el Tribunal parece preocupado sobre todo por mantener la posición que había adoptado en el asunto Chacón Navas ${ }^{28}$ : la noción de discapacidad es la propia de la Directiva, de suerte que, incluso si la legislación cuestionada reconoce a un trabajador como persona con discapacidad, cabe indagar respecto a si su participación plena y efectiva en la vida profesional se muestra afectada. A este respecto, el precedente Kaltoft ${ }^{29}$ no permite asimilar de oficio la obesidad a la discapacidad. Es la jusisdicción nacional quien debe proceder a esta indagación -aspecto que, curiosamente, no figura en la parte dispositiva de la Sentencia del Tribunal-.

En cuanto a la discriminación indirecta, el precedente Ring y Skouboe Werge ${ }^{30}$ guía la decisión: el artículo 2, apartado 2. letra b), inciso i), de la Directiva se opone a una regla susceptible de afectar de modo particular a los trabajadores con discapacidad salvo si tal disposición, al tiempo que persigue el objetivo legítimo de luchar contra el absentismo,

${ }^{27}$ Decisiones TEDH de 6 marzo 2018, Gellérthegyi, Balla and Balláné Gal vs. Hungría, Reqs. n 78135/13 y 429/14; y de 10 abril 2018, Vereš and Kocjančič vs. Eslovenia, Reqs. n 50408/15 y 11727/16.

${ }^{28}$ STJUE de 11 julio 2006, Chacón Navas, C-13/05.

${ }^{29}$ STJUE de 18 diciembre 2014, Kaltoft, C-354/13.

${ }^{30}$ STJUE de 11 abril 2013, Ring y Skouboe Werge, C-335/11 y C-337/11 acumulados. 
no excede de lo necesario para alcanzarlo -lo que no va a ayudar mucho al Juzgado de lo Social de Cuenca-. En todo caso, la evolución de la jurisprudencia del Tribunal de Justicia dedicada a esta causa de discriminación es lenta.

\subsection{Sentencia TEDH de 30 enero 2018, Şahin vs. Turquía, Req. no 23065/12}

Hace tres años, la Gran Sala del TEDH había declarado ${ }^{31}$ la inadmisibilidad por falta de agotamiento de las vías internas de recurso, la petición de un estudiante rumano, afectado de modo sobrevenido por una paraplejia, al que ninguna universidad había querido garantizar los ajustes de acceso necesarios para permitirle la continuidad en su actividad académica. Habíamos comentado que si el Derecho de la Unión Europea hubiera sido invocado durante el litigio ante los tribunales internos, se hubiera debido tener en cuenta la Directiva 2000/78/ $\mathrm{CE}$, aplicable a los estudios seguidos por el recurrente, que eran de formación profesional ${ }^{32}$.

Este precedente negativo no ha sido evocado en un nuevo asunto, cuyos hechos se muestran sin embargo como muy próximos: un estudiante universitario turco sufrió un accidente que le dejó parapléjico. Poco satisfecho ante las soluciones que le propone su facultad para continuar su recorrido académico, impugna la resolución ante el tribunal administrativo, que desestima el recurso. El Consejo de Estado confirma ese criterio.

A solicitud del estudiante, el Tribunal Europeo examina, en la Sentencia analizada, la combinación de los artículos 2 del Primer protocolo (derecho a la instrucción) y 14 de la Convención, y concluyó apreciando una discriminación basada en la discapacidad debida a la atención insuficiente que ha prestado el tribunal a la proteción de los intereses del recurrente. Este obtuvo 10.000 euros a título de indemnización por el daño moral ${ }^{33}$.

El Tribunal inevitablemente se refirió a la Sentencia dictada un par de años antes en otro asunto similar procedente de Turquía ${ }^{34}$, que abordaba el rechazo de un conservatorio a la matrícula de una alumna ciega, que no obstante había sido galardonada en el concurso de acceso. De todos modos, en este caso, el establecimiento educativo no había ofrecido ningún ajuste adecuado para superar los obstáculos debidos a la discapacidad, mientras que, por lo contrario, la facultad involucrada en el nuevo litigio se había mostrado más sensible al problema mediante sus propuestas de solución.

En cuanto a la opinión disidente del Juez Lemmens es meritoria en su análisis. Para este Juez lo que perseguía el recurrente no era obtener las medidas de solución a su caso individual, sino forzar a las autoridades turcas a garantizar, en todas las instituciones educativas, las obras de transformación necesarias para asegurar a todas las personas afectadas por la misma discapacidad que la suya, el ejercicio de sus derechos. Dicho de otro modo, el juez reprocha a sus colegas por haberse concentrado en la noción de ajustes

\footnotetext{
${ }^{31}$ Decisión TEDH de 9 julio 2015, Gherghina vs. Rumanía, Req. $n^{\circ}$ 42219/07; véase también la Decisión de 5 enero 2016, Radi and Gherghina vs. Rumanía, Req. $n^{\circ} 34655 / 14$.

${ }^{32}$ STJUE de 21 junio 1988, Lair, 39/86.

${ }^{33}$ Sentencia que ya es definitiva pues la petición del Gobierno turco de reenvio ante la Gran Sala fue rechazada el 2 de julio de 2018.

${ }^{34}$ STEDH de 23 febrero 2016, Çam vs. Turquía, Req. nº 51500/08.
} 
razonables, que deriva del artículo 12 de la Convención, y no en la de accesibilidad, que deriva del artículo 2 del Primer Protocolo.

\section{Discriminación por razón de las convicciones}

\subsection{Sentencia TJUE de 17 abril 2018, Egenberger, C-414/16}

El Tribunal de Justicia ha tardado tiempo en poder examinar el cuarto criterio de discriminación previsto por la Directiva 2000/78/CE, el de las convicciones ${ }^{35}$. Más recientemente todavía, el Tribunal se ha visto confrontado al anexo particular del artículo 4.2 de la Directiva vinculado a este criterio: el caso de las empresas de tendencia. La cuestión parece de primera importancia pues el Tribunal ha confiado el asunto a su Gran Sala.

La Iglesia evangélica alemana había publicitado una oferta de empleo a fin de contratar a una persona para redactar un informe, paralelo al del Gobierno, dedicado a la Convención de Naciones Unidas sobre la eliminación de todas las formas de discriminación racial. En la oferta, la pertenencia a una iglesia protestante o ser miembro de la comunidad de trabajo de las iglesias cristianas constituía un prerequisito, y el/a candidato o candidata era invitado a identificar su confesión religiosa. Una aspirante sin confesión identificada se postuló para el puesto de trabajo; superó una primera fase de selección pero no fue convocada a la entrevista y el puesto de trabajo acabó siendo adjudicado a un hombre que había precisado su pertenencia a una iglesia protestante. La candidata descartada alega una discriminación basada en sus convicciones e inicia un procedimiento que desemboca ante el Bundesarbeitsgericht, que acude al Tribunal de Justicia.

La diferencia de trato en función de las convicciones no fue objeto de discusión en el caso; el litigio se focalizó sobre la excepción debida a la exigencia profesional esencial y determinante (artículo 4.1 de la Directiva) con la dimensión particular que aporta el apartado 2. El Tribunal establece que este dispositivo complejo, destinado a conciliar el principio de no discriminación en el empleo con el de la libertad de las convicciones en las que se basa la entidad empleadora, significa que la adhesión a esas convicciones debe constituir una exigencia esencial, considerando la naturaleza de las condiciones de ejercicio de esa concreta actividad; asimismo la regla de proporcionalidad se aplica a esta necesidad. Tal formulación parece bastante abstracta y ciertamente al límite de la paráfrasis del contenido, tan cargado como atormentado del artículo 4.2. En sus conclusiones, el Abogado General E. Tanchev sugería una referencia a la jurisprudencia del TEDH de los derechos humanos que había analizado varios casos similares con mucho pragmatismo ${ }^{36}$; sin embargo, el TJUE no se refiere sino a otra Sentencia del TEDH, especialmente discutible ${ }^{37}$.

\footnotetext{
${ }^{35}$ Lo que aconteció con las SSTJUE de 14 marzo 2017, Achbita, C-157/15, y Bougnaoui, C-188/15.

${ }^{36}$ SSTEDH de 23 septiembre 2010, Obst vs. Alemania, req. ${ }^{\circ}$ 425/03, y Schüth vs. Alemania, Req. $n^{\circ} 1620 / 03 ; y$ STEDH de 3 febrero 2011, Siebenhaar vs. Alemania, Req. ${ }^{\circ} 18136 / 02$.

${ }^{37}$ STEDH, Gran Sala, de 12 junio 2014, Fernández Martínez vs. España, Req. n 56030/07, confirmando la Sentencia de la Sala de 15 de mayo de 2012.
} 
Así se ve la jurisdicción alemana encargada de valorar la cuestión a la luz de su disposición nacional, esforzándose a la hora de poner en práctica una interpretación conforme al artículo 4.2 de la Directiva, lo que no debería revelarse demasiado arduo, ya que la normativa interna sigue de cerca la norma europea. Sin embargo, a fin de actuar con mayor seguridad, el Tribunal Federal de Trabajo había querido saber si, en caso de imposibilidad de interpretación conforme, debía inaplicarse la regla errónea.

La respuesta llega ineludible al igual que el desplazamiento de un glaciar (a salvo del calentamiento global). Ya que la norma europea implementa el principio de no discriminación previsto en el artículo 21 de la Carta de los derechos fundamentales de la Unión (combinado con el artíclo 47 que enuncia el derecho a un proceso equitativo), la disposición nacional incompatible debe ser descartada: efecto directo no solo vertical sino horizontal de una directiva. Entre los catorce criterios enumerados en el artículo 21 la vía abierta $^{38}$, consolidada después ${ }^{39}$, en relación al criterio de la edad se extiende así hacia el criterio de las convicciones. Parece pues que un criterio tras el otro acabará por ganar al del sexo, consolidando la supremacía del artículo 21 sobre el 23 ... con la salvedad de que el Tribunal confiese finalmente que reniega de la doctrina del efecto directo (vertical y no horizontal) que estableció ya hace más de treinta $\operatorname{años}^{40}$. Si se me disculpa que vuelva a citarme otra vez: "solo los apasionados del teorema de Fermat desearían ver eternizarse una ambigüedad tan profunda" 41 .

\subsection{Decisión TEDH de 13 marzo 2018, Balo contra Turquía, Req. $n^{\circ}$ 2379/10}

El Tribunal de Estrasburgo declara aquí la inadmisibilidad, por falta de agotamiento de los recursos previos, de una demanda alegando el artículo 6.1 de la Convención (respecto a hechos que habrían permitido el juego de la Directiva 2000/78/CE, de haberse podido aplicar). En Turquía, una joven de dieciséis años había contraído matrimonio religioso con un funcionario, matrimonio que duró trece años, hasta el fallecimiento del esposo; habiendo tenido cinco hijos. Treinta años después del fallecimiento (sin duda, cuando ella alcanzó la edad de la jubilación), la viuda solicitó la concesión retroactiva de una pensión de viudedad (conforme a un régimen de función pública profesional si hubiéramos de calificarlo conforme con los criterios del Derecho de la Unión Europea). El fondo de pensiones rechazó la solicitud porque la legislación solo reconocía el matrimonio civil, siendo la decisión confirmada por las instancias administrativas superiores.

Al no haber entrado en el fondo del litigio, el Tribunal Europeo no se vio obligado a evocar un precedente casi idéntico ${ }^{42}$ en el que la Gran Sala había concluido la ausencia de violación del artículo 14 de la Convención combinado con el artículo 1 del primer pro-

\footnotetext{
${ }^{38}$ STJUE de 22 noviembre 2005, Mangold, C-144/04.

${ }^{39}$ STJUE, Gran Sala, de 19 abril 2016, Rasmussen, C-441/14.

${ }^{40}$ STJUE de 26 febrero 1986, Marshall I, 152/84.

${ }^{41}$ J. Jacqmain, "Article 23 - Égalité entre femmes et hommes" en F. Picod y S. van Drooghenbroeck (dirs.), Charte des droits fondamentaux de l'Union européenne - Commentaire article par article, Bruxelles, Bruylant, 2017, p. 546.

${ }^{42}$ STEDH de 2 noviembre 2010, Yigit vs. Turquía, Req. nº 3976/05.
} 
tocolo, considerando que el artículo 8 (derecho a la vida familiar) no obliga a los Estados firmantes a reconocer los matrimonios religiosos. En ese precedente el Tribunal debería haber explicado las diferencias con un asunto anterior ${ }^{43}$ que le había conducido a una solución inversa: se trataba de la legislación española, que admite que uniones celebradas conforme a ciertas religiones tengan los mismos derechos que el matrimonio civil, al tiempo que las autoridades nacionales no habían podido justificar por qué rechazaban un efecto similar para el matrimonio formalizado según la costumbre gitana.

En conjunto, estos conflictos no han obligado todavía al Tribunal Europeo de Derechos Humanos a abordar diversas cuestiones complejas, como los matrimonios infantiles o la desaparición de los derechos derivados en casos en que la legislación no garantiza a toda persona sus derechos propios ${ }^{44}$.

\subsection{Sentencia TEDH de 24 julio 2018, Negrea vs. Rumanía, Req. 53183/07}

Siguiendo el hilo temático, se añade un asunto que habría merecido un examen en términos de género o de origen étnico, y en Derecho de la Unión, y no solo en Derecho del Consejo de Europa. En Rumanía, diversas mujeres gitanas no habían podido acceder a una prestación de nacimiento destinada a la madre. Según los recursos, la secretaria del ayuntamiento competente en la concesión de la prestación les había reprochado no haber cumplido la condición (no prevista por la legislación) de estar casadas legalmente, en lugar de practicar la unión de pareja de conformidad con las reglas de la comunidad gitana; según la funcionaria, el rechazo estaba motivado por el carácter extemporáneo de las solicitudes. Los procesos civiles y penales impulsados por las interesadas no acogieron sus pretensiones. El Tribunal Europeo se limitó a constatar la violación del artículo 6.1 de la Convención (duración razonable) en combinación con el artículo 13 (falta de recurso efectivo), pero consideró que no se había demostrado la violación del artículo 14 (discriminación) combinado con el 8 (vida familiar), o del artículo 1 del Primer Protocolo.

\section{Discriminaciones más allá del marco general}

\subsection{Sentencia TEDH de 12 diciembre de 2017, Çölgeçen contra Turquía, Req. $n^{\circ}$ 50124/07}

En 2001, siete estudiantes de la Universidad de Estambul habían solicitado la creación de un curso optativo de lengua kurda. Las autoridades académicas sancionarion a los estudiantes con suspensiones o expulsiones. Las medidas fueron posteriormente anuladas por la jurisdicción contencioso-administrativa; por lo contrario, no obtuvieron reparación pecuniaria. Al conocer de sus recursos, el Tribunal Europeo concluyó por 5

\footnotetext{
${ }^{43}$ STEDH de 8 diciembre 2009, Muñoz Díaz vs. España, Req. n 49151/07.

${ }^{44}$ Sobre este tema véase Auto TJUE de 17 marzo 2009, Mariano, C-217/08.
} 
votos contra 2 la concurrencia de una ingerencia desproporcionada en el derecho a la instrucción garantizado por el artículo 2 del Primer Protocolo; pero el Tribunal consideró que no disponía de elementos para realizar un examen respecto al artículo 14 de la Convención.

Dejando de lado el aspecto detestable de la represión autoritaria, ¿podría haberse abordado el caso de otra manera de haberse podido aplicar el Derecho de la Unión Europea? El acceso a la enseñanza superior se incluye dentro de la noción de formación profesional, prevista en en artículo 3.1.b) de las Directivas 2000/43/CE y 2000/78/CE. Sin embargo, la segunda de estas Directivas no cita a la lengua entre las características que prohíbe utilizar con finalidad discriminatorias. En cuanto a la primera, la alegación del criterio del origen étnico parecería tener mayores visos de viabilidad ${ }^{45}$. Pero el hecho de pertenecer a una minoría, incluso nacional, ¿justifica que el derecho a recibir la enseñanza en la lengua de esta minoría pueda imponerse a cada uno de los Estados miembros de la Unión? Se observa que el criterio de la lengua, mencionado en la enumeración abierta del artículo 21.1 de la Carta de los derechos fundamentales aunque sin concreción en el derecho secundario, puede prestarse a litigios futuros.

\subsection{Sentencia TEDH de 5 diciembre 2017, Ribać contra Eslovenia, Req. 57101/10}

El Tribunal de Estrasburgo apreció una violación del artículo 14 de la Convención en combinación con el artículo 1 del Primer Protocolo en un asunto relacionado con la pensión de un militar miembro de las fuerzas armadas de la antigua República federal de Yugoslavia. De nacionalidad serbia, el interesado residía desde 1964 en Eslovenia, habiéndose jubilado allí en 1991. Las autoridades eslovenas le concedieron el derecho a un anticipo de su pensión, pero en 1998 suspedieron su pago y rechazaron pagársela hasta 2003, cuando adquirió la nacionalidad eslovena. Puesto que el interesado había obtenido el derecho a la pensión en base de la legislación entonces en vigor y no era aplicable la causa de exclusión vinculada a la participación en el ataque serbio contra Eslovenia, el rechazo de la pensión fundamentado en la nacionalidad carecía de justificación. El recurrente recibió, a título de indemnización por daño material, una suma equivalente a las pensiones no percibidas y 50.000 euros por el daño moral.

Los hechos son anteriores a la adhesión de Eslovenia a la Unión Europea (1 de mayo de 2004), pero el Derecho de la Unión Europea no habría aportado nada a la solución del litigio ya que su principio general de prohibición de la discriminación por nacionalidad (art. 18 TFUE) no es aplicable a los ciudadanos de Estados no miembros de la Unión, mientras que el criterio de la nacionalidad queda fuera ${ }^{46}$ de la Directiva 2000/78/CE, norma que se habría aplicado a la situación ya que se trataba de una pensión profesional.

\footnotetext{
${ }^{45}$ Si nos atenemos a la STJUE de 6 abril 2017, Jyske Finans A/S, C-668/15.

${ }^{46}$ Véase la STJUE de 14 abril 2012, Kamberaj, C-571/10.
} 
"Any color so long as it is black", había prescrito Henry Ford en 1909 a los candidatos a comprar su "Modelo T". Todavía hoy, "black" puede simbolizar la característica (de toda índole) de $\mathrm{X}$, que tiene el poder, respecto de $\mathrm{Y}$, que no tiene ni uno ni otro. Ciertamente, existen reglas contra tales abusos, pero no puede decirse que todos los Estados miembros o personas pongan su mayor cuidado a la hora de aplicarlas. Ni tampoco que, por causa de sus ambigüedades, reparos y contradicciones, los dos Tribunales europeos aseguren sin descanso la efectividad de esas reglas. 